\title{
Effects of natalizumab treatment on the cerebrospinal fluid proteome of multiple sclerosis patients
}

\author{
Stoop, M P ; Singh, V ; Stingl, C ; Martin, R ; Khademi, M ; Olsson, T ; Hintzen, R Q ; Luider, T M
}

\begin{abstract}
Natalizumab is a very effective, relatively new drug for the treatment of relapsing remitting multiple sclerosis. Inflammatory and neurodegenerative processes in the central nervous system are presumed to cause adverse effects during the course of this disease. To monitor the effects of natalizumab treatment on the cerebrospinal fluid (CSF) proteome of patients, CSF samples were taken from patients before commencing treatment as well as after 1 year of treatment. Profiling proteomics experiments using electrospray Orbitrap mass spectrometry and pair wise comparison of patients before and after 1 year of natalizumab treatment revealed a number of candidate biomarkers that were significantly differentially abundant between the before and after treatment groups. Three proteins were subsequently validated using selected reaction monitoring (SRM) in a new, independent sample set. All three proteins, Ig mu chain $\mathrm{C}$ region and haptoglobin, both known inflammation-related proteins, as well as Chitinase-3-like protein 1, were confirmed by SRM to be significantly lower abundant in CSF of multiple sclerosis patients after 1 year of natalizumab treatment. The findings for Chitinase-3-like protein 1, a presumed biomarker for more rapid progression from a first clinically isolated syndrome to clinically definite multiple sclerosis, was further confirmed by ELISA measurements.
\end{abstract}

DOI: https://doi.org/10.1021/pr3012107

Posted at the Zurich Open Repository and Archive, University of Zurich

ZORA URL: https://doi.org/10.5167/uzh-85436

Journal Article

Accepted Version

Originally published at:

Stoop, M P; Singh, V; Stingl, C; Martin, R; Khademi, M; Olsson, T; Hintzen, R Q; Luider, T M (2013). Effects of natalizumab treatment on the cerebrospinal fluid proteome of multiple sclerosis patients. Journal of Proteome Research, 12(3):1101-1107.

DOI: https://doi.org/10.1021/pr3012107 


\section{Effects of natalizumab treatment on the CSF proteome of multiple sclerosis patients}

Marcel P. Stoop ${ }^{1}$, Vaibhav Singh ${ }^{1}$, Christoph Stingl ${ }^{1}$, Roland Martin ${ }^{2,3}$, Mohsen Khademi ${ }^{4}$, Tomas Olsson ${ }^{4}$, Rogier Q. Hintzen ${ }^{1}$, and Theo M. Luider ${ }^{1}$

1- Department of Neurology, Erasmus MC, Rotterdam, the Netherlands

2- Institute for Neuroimmunology and Clinical Multiple Sclerosis Research, University Medical Center-Eppendorf, Hamburg, Germany

3- Department of Neuroimmunology and Multiple Sclerosis Research, Neurology Clinic, University Hospital Zürich, Zürich, Switzerland 4 - Department of Clinical Neuroscience, Neuroimmunology Unit, Karolinska University Hospital, Stockholm, Sweden

Corresponding author:

Theo M. Luider

Laboratories of Neuro-Oncology/Clinical and Cancer Proteomics

Department of Neurology

Erasmus University Medical Centre

Dr. Molewaterplein 50

3015 GE Rotterdam

The Netherlands

e-mail: t.luider@erasmusmc.nl

Phone: +(31) 107038069

Fax: +(31) 107044365 : 


\section{List of abbreviations}

ACN - acetonitrile

CNS - central nervous system

CSF - cerebrospinal fluid

Da - dalton

ESI - electrospray ionization

FA - formic acid

ID - internal diameter

$\mathrm{MScl} \quad$ - multiple sclerosis

MS/MS - tandem mass spectrometry

ppm - parts-per-million

$\mathrm{RR} \quad$ - relapsing remitting

SRM - selected reaction monitoring

TFA - triflouroacetic acid 


\section{Abstract}

Natalizumab is a very effective, relatively new drug for the treatment of relapsing remitting multiple sclerosis. Inflammatory and neurodegenerative processes in the central nervous system are presumed to cause adverse effects during the course of this disease. To monitor the effects of natalizumab treatment on the cerebrospinal fluid (CSF) proteome of patients, CSF samples were taken from patients before commencing treatment as well as after one year of treatment.

Profiling proteomics experiments using electrospray Orbitrap mass spectrometry and pair wise comparison of patients before and after treatment revealed a number of candidate biomarkers that were significantly differentially abundant between the before- and after treatment groups. Three proteins were subsequently validated using selected reaction monitoring (SRM) in a new, independent sample set. All three proteins, Ig mu chain $\mathrm{C}$ region and haptoglobin, both known inflammation-related proteins, as well as chitinase-3-like protein 1, were confirmed by SRM to be significantly lower abundant in CSF of multiple sclerosis patients after one year of natalizumab treatment. The findings for chitinase-3-like protein 1, a presumed biomarker for conversion of clinically isolated syndrome to clinically definite multiple sclerosis, was further confirmed by ELISA measurements. 


\section{Introduction}

Multiple sclerosis ( $\mathrm{MScl}$ ) is a common cause of neurological disability in young adults. The cause of the severe neurological disability is the interruption of myelinated tracts in the central nervous system $(\mathrm{CNS})^{1}$. Most pathogenesis models for the disease support the existence of two connected processes that occur in patients with MScl; inflammation and neurodegeneration ${ }^{2}$. These processes are not uniformly represented across patient populations but can predominate selectively in individual patients, contributing to the heterogeneity of phenotypic expression of the disease $^{3}$. The majority (approximately $85 \%$ ) of MScl patients have the relapsing remitting (RR) MScl subtype of the disease ${ }^{4}$. RR MScl is characterized by relapses with increased disease activity, which occur at irregular intervals, followed by periods of remission. It is believed that the disease process starts with increased migration of auto-reactive lymphocytes across the blood-brain barrier ${ }^{5}$.

Treatment for RR MScl is focused on the reduction of the number of relapses. These therapeutic agents, such as interferon beta and glatiramer acetate, are only moderately effective and reduce the annualized relapse rate by about a third ${ }^{6-7}$. The monoclonal antibody natalizumab (brand name: Tysabri) is an effective agent in the prevention of clinical relapses in relapsing remitting multiple sclerosis patients, reducing the relapse rate by $68 \%{ }^{8}$. The therapeutic effect of natalizumab is thought to be mediated by suppression of leukocyte migration into the central nervous system by blocking the Very-Late Activation Antigen 4 ligand on immune cells ${ }^{9}$. As a consequence, a reduction of inflammation and inflammatory mediators might be observable in the central nervous system of natalizumab treated patients. However, neurodegeneration-related proteins were recently also reported to be influenced by natalizumab treatment ${ }^{10}$.

In this study, we employed state-of-the-art quantitative proteomics techniques to differentiate between cerebrospinal fluid (CSF) samples of multiple sclerosis patients before and after treatment with natalizumab.

\section{Methods}

CSF samples were taken from relapsing remitting MScl patients before natalizumab treatment commenced at the University Medical Center Eppendorf (Hamburg, Germany). The post-treatment samples were taken at the same hospital one year 
after the start of Tysabri treatment. The Tysabri treatment consisted of a year-long treatment of monthly natalizumab infusion (300 mg intravenously, infused over approximately one hour, every four weeks). All patients gave their consent for the repeated CSF sampling. Immediately after sampling, the CSF samples were centrifuged for $10 \mathrm{~min}$ at $3000 \mathrm{rpm}$ to discard cells and cellular elements. The samples were subsequently used for routine CSF diagnostics, which included quantification of total protein concentration (table 1). The remaining volume of the samples was aliquoted and stored at $-80^{\circ} \mathrm{C}$, where they remained until sample preparation for this study. The sample details are listed in table 1 (discovery sample set column).

From each CSF sample, $20 \mu \mathrm{L}$ was added to $20 \mu \mathrm{L}$ of $0.2 \%$ Rapigest (Waters, Milford, MA) in $50 \mathrm{mM}$ ammonium bicarbonate buffer. After 30 min incubation periods with 1,4-dithiothreitol $\left(60^{\circ} \mathrm{C}\right)$ and, subsequently, iodoacetamide $\left(37^{\circ} \mathrm{C}\right), 4 \mu \mathrm{L}$ of 0.1 $\mu \mathrm{g} / \mu \mathrm{L}$ gold-grade trypsin (Promega, Madison, WI)/3 mM Tris-HCl ( $\mathrm{pH}$ 8.0) was added to each sample. The samples were incubated overnight at $37^{\circ} \mathrm{C}$. To adjust the $\mathrm{pH}$ of the digest to $\mathrm{pH}<2$, trifluoroacetic acid (TFA) was added to the mixture prior to the final incubation step at $37{ }^{\circ} \mathrm{C}$ for a duration of 45 minutes to stop the enzymatic digestion reaction.

Mass spectrometry measurements were carried out on a Ultimate 3000 nano LC system (Dionex, Germering, Germany) online coupled to a hybrid linear ion trap/Orbitrap MS (LTQ Orbitrap XL; Thermo Fisher Scientific, Germany). Five $\mu \mathrm{L}$ digest were loaded on to a C18 trap column (C18 PepMap, $300 \mu \mathrm{m} \mathrm{ID} \times 5 \mathrm{~mm}, 5 \mu \mathrm{m}$ particle size, $100 \AA$ pore size; Dionex, The Netherlands) and desalted for 10 minutes using a flow rate of $20 \mu \mathrm{L} / \mathrm{min} 0.1 \%$ TFA. Then the trap column was switched online with the analytical column (PepMap C18, $75 \mu \mathrm{m} \mathrm{ID} \times 150 \mathrm{~mm}, 3 \mu \mathrm{m}$ particle and 100 $\AA$ pore size; Dionex, The Netherlands) and peptides were eluted with following binary gradient: $0 \%-25 \%$ solvent $B$ in $120 \mathrm{~min}$ and $25 \%-50 \%$ solvent $B$ in further 60 minutes, where solvent $A$ consist of $2 \%$ acetonitrile and $0.1 \%$ formic in water and solvent $B$ consists of $80 \%$ acetonitrile and $0.08 \%$ formic acid in water. Column flow rate was set to $300 \mathrm{~nL} / \mathrm{min}$. For MS detection a data dependent acquisition method was used: high resolution survey scan from 400-1800 Th. was performed in the Orbitrap (value of target of automatic gain control AGC $10^{6}$, resolution 30,000 at 400 $\mathrm{m} / \mathrm{z}$; lock mass was set to $445.120025 \mathrm{u}$ (protonated $\left.\left(\mathrm{Si}_{(}\left(\mathrm{CH}_{3}\right)_{2} \mathrm{O}\right)_{6}{ }^{11}\right)$. Based on this survey scan the 5 most intensive ions were consecutively isolated (AGC target set to 
$10^{4}$ ions) and fragmented by collision-activated dissociation (CAD) applying 35\% normalized collision energy in the linear ion trap. After precursors were selected for MS/MS, they were excluded for further MS/MS spectra for 3 minutes.

The raw data was pre-processed using the Progenesis LC-MS software package (version 2.6, Nonlinear Dynamics, Newcastle-upon-Tyne, United Kingdom). Peptides were identified and assigned to proteins by exporting features, for which MS/MS spectra were recorded, using the Bioworks software package (version 3.2; Thermo Fisher Scientific, Germany; peak picking by Extract_msn, default settings). The resulting .mgf file was submitted to Mascot (version 2, Matrix Science, London, United Kingdom) for identification to interrogate the UniProt-database (release 2010_04; taxonomy: Homo sapiens, containing 77399 sequences). Only ions with charge states between +2 and +7 were considered and only proteins with at least two unique peptides (Mascot sore $>25$ ) assigned to them were accepted as true identifications. Modifications: carbamidomethylation of cysteine was set as fixed and oxidation of methionine as variable modification, allowing a maximum of 2 missed cleavages. Mass tolerance for precursor ions was set to $10 \mathrm{ppm}$ and for fragment ions at $0.5 \mathrm{Da}$. The Mascot search results were imported back into the Progenesis software to link the identified peptides to the detected abundances of these peptides. Subsequently the data were exported in Excel format.

The raw abundances of all identified peptides were compared between the groups of samples (before and after treatment with natalizumab) by performing a paired $t$-test on all individual peptides. Proteins of which $50 \%$ or more of the peptides had a low pvalue in this t-test $(p<0.01)$ were deemed to be significantly differentially abundant between the two groups.

\section{Validation by Selected Reaction Monitoring}

To validate the found differentially abundant proteins a validation sample set of CSF samples of natalizumab treated patients was collected at the Karolinska Institute in Stockholm, Sweden. The CSF samples, which were taken from 20 patients both before and after treatment were stored at $-80^{\circ} \mathrm{C}$ before shipping on dry ice to the analysis laboratory (Table 1 ). Subsequently these samples were enzymatically digested following the exact same protocol as used for the original samples. The digested CSF samples were spiked with known concentrations of stable isotopelabelled peptide standards corresponding to sequences 100-112 (NVPLPVIAELPPK) 
and 113-120 (VSVFVPPR) of Ig mu chain C region (P01871), sequences 119-131 (TEGDGVYTLNNEK) and 162-170 (ILGGHLDAK) of haptoglobin (P00738), and sequences 322-335 (GNQWVGYDDQESVK) and 370-377 (FPLTNAIK) of chitinase3-like protein 1 (P36222) for quantification by selected reaction monitoring (SRM).

Peptides in spiked CSF digests were separated by reversed-phase chromatography on an Ultimate 3000 nano LC system (Dionex). Spiked CSF digest $(1 \mu \mathrm{L})$ was loaded onto a C18 trap column (PepMap C18, $300 \mu \mathrm{m}$ ID by $5 \mathrm{~mm}$ length, $5 \mu \mathrm{m}$ particle size and $100 \AA$ pore size; Dionex) and washed for $5 \mathrm{~min}$ at a flow rate of $20 \mu \mathrm{L} / \mathrm{min}$ with $0.1 \%$ TFA in $\mathrm{H}_{2} \mathrm{O}$. Next, the trap column was switched in line with the analytical column (PepMap C18, $75 \mu \mathrm{m}$ ID by $150 \mathrm{~mm}$ length, $3 \mu \mathrm{m}$ particle size and $100 \AA$ pore size; Dionex). Peptides were eluted at a flow rate of $300 \mathrm{~nL} / \mathrm{min}$ with the following gradient: $0 \%-45 \%$ solvent $B$ in 30 min, where solvent $A$ is $\mathrm{H}_{2} \mathrm{O}$ /acetonitrile (ACN) $98 \% / 2 \%$ (vol/vol), $0.1 \%$ formic acid (FA) and solvent $\mathrm{B}$ is $\mathrm{H}_{2} \mathrm{O} / \mathrm{ACN} 20 \% / 80 \%$ $(\mathrm{vol} / \mathrm{vol}), 0.1 \% \mathrm{FA}$. Separation of the peptides was monitored with a UV detector (absorption at $214 \mathrm{~nm}$ ).

SRM analysis was performed on an ESI triple quadrupole (ESI-QqQ) tandem mass spectrometer (4000 QTRAP; AB Sciex, Concord, Canada) in the positive ion mode. Three transitions were quantified for all peptides (NVPLPVIAELPPK, transitions y3, y9, and y11; VSVFVPPR, transitions y3, y4 and y5; ILGGHLDAK, transitions b6, b7 and $y 7$; GNQWVGYDDQESVK, transitions $y 7$, y8 and y9; and FPLTNAIK, transitions $y 5, y 6$ and $y 7)$. No transitions could be quantified for the TEGDGVYTLNNEK peptide of haptoglobin, as this peptide could not be detected on the ESI-QqQ. Hence haptoglobin was quantified on the values obtained for the ILGGHLDAK peptide only. We performed data analysis using the SRM data analysis program Skyline (version 1.1). Concentrations of the analyte peptides were determined based on the ratio between the peak area of the analyte peptide to the peak area of the spiked isotopelabelled internal peptide standard, which was added at a known concentration.

\section{Validation of Chitinase-3-like protein 1 by ELISA}

To further confirm the differential abundance of chitinase-3-like protein 1 between untreated and natalizumab treated multiple sclerosis patients, an ELISA for this protein was purchased, and performed according to the manufacturers (R\&D Systems, Abingdon, United Kingdom) instructions. 


\section{Results}

Using ESI-Orbitrap mass spectrometry a total of 3289 peptides were identified during the measurements of the "before treatment" and "after treatment" CSF samples of the seventeen relapsing remitting multiple sclerosis patients in the discovery sample set. These peptides relate to 578 unique proteins, of which 301 were identified by 2 or more peptides. Using a paired t-test to compare the CSF samples from before treatment to the samples from after treatment, 122 peptides had a p-value below 0.01 (statistical background determined by permutation: 33+/- 21). For fourteen proteins $50 \%$ or more of the peptides had a p-value lower than 0.01 , fulfilling the pre-set criterion for differential abundance (Table 2). Of these proteins five were identified by multiple peptides, namely haptoglobin, Ig mu chain $\mathrm{C}$ region, Ig mu heavy chain disease protein, serine protease inhibitor and scavenger receptor cysteine-rich type 1 protein M130.

Additionally, chitinase-3-like protein 1, a potential CSF marker for conversion of clinically isolated syndrome of demyelination (CIS) to clinically definite $\mathrm{MScl}^{12}$, was identified by eleven unique peptides. One of these peptides had a significant $p$-value in the statistical analysis, and an additional six peptides showed low, nearly significant $p$-values (between 0.016 and 0.071). All peptides of chitinase-3-like protein 1 were decreased in the Orbitrap measurements of the CSF samples after treatment. Hence, although not statistically significant according to the predetermined criteria, this protein did show a trend towards statistical significance. Because this protein has been previously implicated as a conversion factor for $\mathrm{CIS}$ to $\mathrm{MScl}$, we decided to include chitinase-3-like protein 1 in the validation stage of the study.

The majority of proteins related to the inflammatory response, including previously reported potential markers for multiple sclerosis complement $\mathrm{C} 3$, complement $\mathrm{C} 4$ and clusterin $^{13}$, were lower abundant after natalizumab treatment, although this did not reach statistical significance, with the exception of haptoglobin and the immunoglobulin proteins listed in table 2. Previously reported markers of neurodegenerative processes, chromogranin A and contactin- $1^{14}$, were not significantly changed after treatment, although both proteins were higher abundant after treatment. None of the four proteins reported to be decreased in abundance after six months of natalizumab treatment by Ottervald et al. ${ }^{10}$ was statistically significantly changed after six months of natalizumab treatment. Alpha-1 
antichymotrypsin was slightly less abundant after treatment and the other three proteins, contactin-1, neuronal cell adhesion molecule and neural cell adhesion molecule 1, were slightly more abundant after treatment

Three proteins, haptoglobin, Ig my chain $\mathrm{C}$ region and chitinase-3-like protein 1 , were selected for validation using SRM. This validation procedure showed that the peptides of these proteins were significantly lower in concentration in CSF of MScl patients after treatment with natalizumab in a new, independent sample set $(p=$ 0.038 and $p=0.044$ for chitinase-3-like protein $1, p=0.024$ and $p=0.025$ for $\lg \mathrm{mu}$ chain $C$ region, and $p=0.002$ for haptoglobin, Figure 1 ), confirming the results obtained by the ESI-Orbitrap.

Additionally, an ELISA for chitinase-3-like protein 1 was performed for further confirmation, which showed a significant decrease in abundance of this protein after treatment $(p=0.004)$ in CSF of MScl patients in the validation sample set (Figure 2).

\section{Discussion}

In this study, we analyzed the CSF proteome of $\mathrm{MScl}$ patients treated with natalizumab to assess the effects of the drug on the proteins in the CSF by comparing paired samples from patients before treatment and twelve months after treatment. Overall the changes in the CSF proteome after twelve months treatment with natalizumab were limited, but we were able to make a number of interesting observations.

The observation that the proteins related to inflammation are less abundant in CSF after natalizumab treatment is in line with the proposed mechanism of action of the drug $^{15}$. Natalizumab, a humanized monoclonal IgG4K antibody, selectively binds to the a4-integrin component of adhesion molecules found on lymphocytes and monocytes. This binding inhibits interaction with cells expressing the ligand of VLA-4, vascular cell adhesion molecule-1 (VCAM-1), consequently blocking adherence of activated leukocytes to endothelial cells, which is a required step of the extravasation into inflamed tissue ${ }^{16}$. Hence inflammation is inhibited in MScl patients due to the fact that natalizumab prevents the migration of autoreactive leukocytes out of blood vessels into target organs, such as the CNS, by blocking the adhesion molecules of the a4-integrin component of adhesion molecules on leukocytes. 
Also in line with the proposed mechanism of natalizumab is the lack of significantly differentially abundant neurodegenerative proteins after treatment. As the drug mechanism firmly points towards an effect on the inflammatory part of the disease processes, an effect on neurodegeneration was not directly expected to be observed here. Although a previous study shows that axonal damage in $\mathrm{MScl}$ is reduced by natalizumab treatment, it is anticipated that a highly effective anti-inflammatory treatment reduces axonal loss, as inflammatory activity is associated with axonal damage ${ }^{17}$. Consequently, these neurodegenerative effects are likely secondary to inflammatory processes. In contrast to the study by Ottervald and co-workers, in the presented study CSF samples from 6 months after the start of natalizumab treatment were not included $^{10}$. The neurodegeneration-related proteins, alpha-1 antichymotrypsin, contactin-1, neuronal cell adhesion molecule and neural cell adhesion molecule 1, which Ottervald et al. described as significantly less abundant after six months of treatment, but not after twelve months treatment, were not significantly differentially abundant after twelve months of natalizumab treatment in our study. Since no CSF samples were taken after six months of natalizumab treatment and analysed in this study, as well as the fact that the experimental procedures differed substantially between the studies, it is difficult to compare them. Three of the four proteins were even slightly higher abundant after treatment, although these values did not reach significant levels. Hence, no proteins that had previously been related to neurodegenerative effects in MScl could be observed in CSF to be affected by natalizumab treatment in this study.

The majority of differentially abundant proteins found to be less abundant after natalizumab treatment (Table 2) is related to the inflammatory response, which is in the pathogenetic hallmark of MScl. Consequently, the observation that inflammatory response-related proteins with a known higher abundance in CSF of $\mathrm{MSCl}$ patients such as immunoglobulins and haptoglobin ${ }^{18}$ are downregulated after treatment with a drug that blocks the entry of inflammatory cells into the CNS and the subsequent inflammatory effects stands to reason. All proteins identified as significantly higher abundant after treatment were only identified by a single peptide, which is less reliable than identification by multiple peptides. Two of the differentially abundant proteins, haptoglobin and $\mathrm{lg} \mathrm{mu}$ chain $\mathrm{C}$ region (both lower abundant after treatment), were subsequently validated by a different, quantitative mass spectrometry method in an independent data set. The validation experiment 
confirmed the Orbitrap profiling results for both proteins even though one of the peptides of haptoglobin could not be quantified for technical reasons.

The third and final protein that was quantified in the SRM validation experiment, chitinase 3-like protein 1, was not significantly differentially abundant according to the stringent criteria set for the Orbitrap profiling experiments $(p<0.01$ for $50 \%$ of the peptides of a protein). However the fact that a clear trend towards statistical significance could be observed, coupled with a report that chitinase 3-like protein 1 is a potential marker for conversion of CIS to clinically definite $\mathrm{MScl}^{12}$, prompted the inclusion of this protein in the validation experiment. Both the validation by SRM (2 peptides, $p=0.038$ and $p=0.044)$ as well as by ELISA $(p=0.004)$ confirmed the Orbitrap profiling experiment. The difference $p$-values between the validation (statistically significant) and profiling (not statistically significant) experiments is most likely due to the selectivity of the validation method, as accurate quantification is more reliable using targeted methods such as SRM and ELISA, compared to untargeted methods like full scan label free Orbitrap measurements.

Chitinase 3-like protein 1, which is also known as YKL40, is a chitin-binding, but chitinase activity-lacking member of the glycoside hydrolase 18 chitinase family ${ }^{19}$. One of the main cell types that secretes this protein are macrophages, linking the protein to the inflammatory response. Increased abundance of this protein in all likelihood is not specific for conversion of CIS to $\mathrm{MScl}$ or response to natalizumab treatment in $\mathrm{MScl}$ patients, but rather a marker for inflammatory activity in the affected compartment, which is supported by the observation of increased levels in serum of several types of cancers and diseases such as rheumatoid arthritis ${ }^{20-22}$. Additionally, the role of the chitinase family in the pathogenesis of $\mathrm{MScl}$ is further exemplified by the observation of increased plasma levels of chitotriodase in $\mathrm{MScl}$ patients compared to controls ${ }^{23-24}$.

In conclusion, natalizumab treatment of $\mathrm{MScl}$ patients results in a decrease in the levels of inflammation-related proteins in the CSF, which is in line with the proposed mechanism of action of natalizumab. CSF proteins related to neurodegeneration were not affected by natalizumab treatment. A decrease in the CSF levels of chitinase 3-like protein 1, a potential marker for conversion of CIS to clinically definite $\mathrm{MScl}$, was also observed in the patients after twelve months treatment with natalizumab. 


\section{References}

1. Oksenberg, J. R.; Baranzini, S. E.; Sawcer, S.; Hauser, S. L., The genetics of multiple sclerosis: SNPs to pathways to pathogenesis. Nat Rev Genet 2008, 9, (7), 516-26.

2. Hauser, S. L.; Oksenberg, J. R., The neurobiology of multiple sclerosis: genes, inflammation, and neurodegeneration. Neuron 2006, 52, (1), 61-76.

3. Bielekova, B.; Martin, R., Development of biomarkers in multiple sclerosis. Brain 2004, 127, (Pt 7), 1463-78.

4. $\quad$ Miller, D. H.; Leary, S. M., Primary-progressive multiple sclerosis. Lancet Neurol 2007, 6, (10), 903-12.

5. Compston, A.; Coles, A., Multiple sclerosis. Lancet 2008, 372, (9648), 1502-17.

6. Jacobs, L. D.; Cookfair, D. L.; Rudick, R. A.; Herndon, R. M.; Richert, J. R.; Salazar, A. M.; Fischer, J. S.; Goodkin, D. E.; Granger, C. V.; Simon, J. H.; Alam, J. J.; Bartoszak, D. M.; Bourdette, D. N.; Braiman, J.; Brownscheidle, C. M.; Coats, M. E.; Cohan, S. L.;

Dougherty, D. S.; Kinkel, R. P.; Mass, M. K.; Munschauer, F. E., 3rd; Priore, R. L.; Pullicino, P. M.; Scherokman, B. J.; Whitham, R. H.; et al., Intramuscular interferon beta-1a for disease progression in relapsing multiple sclerosis. The Multiple Sclerosis Collaborative Research Group (MSCRG). Ann Neurol 1996, 39, (3), 285-94.

7. Johnson, K. P.; Brooks, B. R.; Cohen, J. A.; Ford, C. C.; Goldstein, J.; Lisak, R. P.; Myers, L. W.; Panitch, H. S.; Rose, J. W.; Schiffer, R. B., Copolymer 1 reduces relapse rate and improves disability in relapsing-remitting multiple sclerosis: results of a phase III multicenter, double-blind placebo-controlled trial. The Copolymer 1 Multiple Sclerosis Study Group. Neurology 1995, 45, (7), 1268-76.

8. Polman, C. H.; O'Connor, P. W.; Havrdova, E.; Hutchinson, M.; Kappos, L.; Miller, D. H.; Phillips, J. T.; Lublin, F. D.; Giovannoni, G.; Wajgt, A.; Toal, M.; Lynn, F.; Panzara, M. A.; Sandrock, A. W., A randomized, placebo-controlled trial of natalizumab for relapsing multiple sclerosis. $N$ Engl J Med 2006, 354, (9), 899-910.

9. Yednock, T. A.; Cannon, C.; Fritz, L. C.; Sanchez-Madrid, F.; Steinman, L.; Karin, N., Prevention of experimental autoimmune encephalomyelitis by antibodies against alpha 4 beta 1 integrin. Nature 1992, 356, (6364), 63-6.

10. Ottervald, J.; Franzen, B.; Nilsson, K.; Andersson, L. I.; Khademi, M.; Eriksson, B.; Kjellstrom, S.; Marko-Varga, G.; Vegvari, A.; Harris, R. A.; Laurell, T.; Miliotis, T.;

Matusevicius, D.; Salter, H.; Ferm, M.; Olsson, T., Multiple sclerosis: Identification and clinical evaluation of novel CSF biomarkers. J Proteomics 2010, 73, (6), 1117-32.

11. Olsen, J. V.; de Godoy, L. M.; Li, G.; Macek, B.; Mortensen, P.; Pesch, R.; Makarov, A.; Lange, O.; Horning, S.; Mann, M., Parts per million mass accuracy on an Orbitrap mass spectrometer via lock mass injection into a C-trap. Mol Cell Proteomics 2005, 4, (12), 201021.

12. Comabella, M.; Fernandez, M.; Martin, R.; Rivera-Vallve, S.; Borras, E.; Chiva, C.; Julia, E.; Rovira, A.; Canto, E.; Alvarez-Cermeno, J. C.; Villar, L. M.; Tintore, M.;

Montalban, X., Cerebrospinal fluid chitinase 3-like 1 levels are associated with conversion to multiple sclerosis. Brain 2010, 133, (Pt 4), 1082-93.

13. Stoop, M. P.; Dekker, L. J.; Titulaer, M. K.; Lamers, R. J.; Burgers, P. C.; Sillevis Smitt, P. A.; van Gool, A. J.; Luider, T. M.; Hintzen, R. Q., Quantitative matrix-assisted laser desorption ionization-fourier transform ion cyclotron resonance (MALDI-FT-ICR) peptide profiling and identification of multiple-sclerosis-related proteins. J Proteome Res 2009, 8, (3), 1404-14. 
14. Stoop, M. P.; Dekker, L. J.; Titulaer, M. K.; Burgers, P. C.; Sillevis Smitt, P. A.; Luider, T. M.; Hintzen, R. Q., Multiple sclerosis-related proteins identified in cerebrospinal fluid by advanced mass spectrometry. Proteomics 2008, 8, (8), 1576-85.

15. Selewski, D. T.; Shah, G. V.; Segal, B. M.; Rajdev, P. A.; Mukherji, S. K., Natalizumab (Tysabri). AJNR Am J Neuroradiol 2010, 31, (9), 1588-90.

16. Ley, K.; Laudanna, C.; Cybulsky, M. I.; Nourshargh, S., Getting to the site of inflammation: the leukocyte adhesion cascade updated. Nat Rev Immunol 2007, 7, (9), 67889.

17. Gunnarsson, M.; Malmestrom, C.; Axelsson, M.; Sundstrom, P.; Dahle, C.; Vrethem, M.; Olsson, T.; Piehl, F.; Norgren, N.; Rosengren, L.; Svenningsson, A.; Lycke, J., Axonal damage in relapsing multiple sclerosis is markedly reduced by natalizumab. Ann Neurol 2011, $69,(1), 83-9$.

18. Zhang, H. L.; Zhang, X. M.; Mao, X. J.; Deng, H.; Li, H. F.; Press, R.; Fredrikson, S.; Zhu, J., Altered cerebrospinal fluid index of prealbumin, fibrinogen, and haptoglobin in patients with Guillain-Barre syndrome and chronic inflammatory demyelinating polyneuropathy. Acta Neurol Scand 2012, 125, (2), 129-35.

19. Renkema, G. H.; Boot, R. G.; Au, F. L.; Donker-Koopman, W. E.; Strijland, A.; Muijsers, A. O.; Hrebicek, M.; Aerts, J. M., Chitotriosidase, a chitinase, and the 39-kDa human cartilage glycoprotein, a chitin-binding lectin, are homologues of family 18 glycosyl hydrolases secreted by human macrophages. Eur J Biochem 1998, 251, (1-2), 504-9.

20. Jensen, B. V.; Johansen, J. S.; Price, P. A., High levels of serum HER-2/neu and YKL40 independently reflect aggressiveness of metastatic breast cancer. Clin Cancer Res 2003, 9 , (12), 4423-34.

21. Kucur, M.; Isman, F. K.; Balci, C.; Onal, B.; Hacibekiroglu, M.; Ozkan, F.; Ozkan, A., Serum YKL-40 levels and chitotriosidase activity as potential biomarkers in primary prostate cancer and benign prostatic hyperplasia. Urol Oncol 2008, 26, (1), 47-52.

22. Vos, K.; Steenbakkers, P.; Miltenburg, A. M.; Bos, E.; van Den Heuvel, M. W.; van Hogezand, R. A.; de Vries, R. R.; Breedveld, F. C.; Boots, A. M., Raised human cartilage glycoprotein-39 plasma levels in patients with rheumatoid arthritis and other inflammatory conditions. Ann Rheum Dis 2000, 59, (7), 544-8.

23. Comabella, M.; Dominguez, C.; Rio, J.; Martin-Gallan, P.; Vilches, A.; Vilarrasa, N.; Espejo, C.; Montalban, X., Plasma chitotriosidase activity in multiple sclerosis. Clin Immunol 2009, 131, (2), 216-22.

24. Sotgiu, S.; Barone, R.; Arru, G.; Fois, M. L.; Pugliatti, M.; Sanna, A.; Rosati, G.; Musumeci, S., Intrathecal chitotriosidase and the outcome of multiple sclerosis. Mult Scler 2006, 12, (5), 551-7. 
Table 1: Details of all patients and related samples included in this study (discovery and validation sample sets). The values for age, disease duration, EDSS score (Expanded Disability Status Scale) and protein concentrations are averages (with standard deviation in brackets). In both sample sets the change in EDSS , as well as the protein concentration in the discovery sample set, from before treatment to after treatment is not significant $(p>0.01)$.

\begin{tabular}{|l|l|l|}
\hline & Discovery set samples (Germany) & Validation set samples (Sweden) \\
\hline Gender distribution (M/F) & $4 / 13$ & $5 / 15$ \\
\hline Age (years) & $37.1(8.1)$ & $41.4(9.8)$ \\
\hline Disease duration (years) & $8.4(5.8)$ & $11.2(6.6)$ \\
\hline EDSS before treatment & $3.7(1.3)$ & $4.3(1.9)$ \\
\hline EDSS after treatment & $3.6(1.4)$ & $4.2(1.9)$ \\
\hline $\begin{array}{l}\text { Protein concentration before treatment } \\
(\mathrm{mg} / \mathrm{L})\end{array}$ & $381.7(75.1)$ & - \\
\hline $\begin{array}{l}\text { Protein concentration after treatment } \\
(\mathrm{mg} / \mathrm{L})\end{array}$ & $318.8(87.3)$ & - \\
\hline
\end{tabular}


Table 2: The fourteen peptides identified as differentially abundant between the "before treatment" and "after treatment" groups.

\begin{tabular}{|l|l|l|l|}
\hline $\begin{array}{l}\text { Primary } \\
\text { accession } \\
\text { number }\end{array}$ & Protein & $\begin{array}{l}\text { Number of peptides } \\
\text { with } p<0.01 / \text { total } \\
\text { number of peptides }\end{array}$ & $\begin{array}{l}\text { Higher abundant } \\
\text { in group }\end{array}$ \\
\hline P00738 & Haptoglobin & $15 / 26$ & Before treatment \\
\hline P01591 & Immunoglobulin J chain & $1 / 1$ & Before treatment \\
\hline P01606 & Ig kappa chain V-I region OU & $1 / 1$ & Before treatment \\
\hline P01871 & Ig mu chain C region & $7 / 12$ & Before treatment \\
\hline P04220 & Ig mu heavy chain disease protein & $1 / 2$ & Before treatment \\
\hline P05154 & Serine protease inhibitor & $1 / 2$ & Before treatment \\
\hline P08133 & Annexin A6 & $1 / 1$ & Before treatment \\
\hline Q86VB7 & Scavenger receptor cysteine-rich type 1 protein M130 & $1 / 2$ & Before treatment \\
\hline P07108 & Acyl-CoA-binding protein & $1 / 1$ & After treatment \\
\hline P32004 & Neural cell adhesion molecule L1 & $1 / 1$ & After treatment \\
\hline Q5FWE3 & Proline-rich transmembrane protein 3 & $1 / 1$ & After treatment \\
\hline Q8IZJ4 & Ral-GDS-related protein & $1 / 1$ & After treatment \\
\hline Q8WXK8 & Bullous pemphigoid antigen 1, isoform 7 (fragment) & $1 / 1$ & After treatment \\
\hline Q9BQT9 & Calsyntenin-3 & $1 / 1$ & After treatment \\
\hline
\end{tabular}




\section{Figure legends}

\section{Figure 1}

SRM results for the three proteins selected for validation. Panels $A$ and $B$ show two peptides of chitinase 3 -like protein 1 to be significantly lower abundant in CSF after natalizumab treatment $(p=0.038$ and $p=0.044)$. Panels $C$ and $D$ show the same for two peptides of $\lg$ mu chain $C$ region $(p=0.024$ and $p=0.025$ ). Panel $E$ shows the ILGGHLDAK peptide of haptoglobin to be significantly lower abundant after treatment $(p=0.002)$. All $p$-values were obtained using a paired t-test as these samples are paired CSF samples from the same patients before and after treatment.

\section{Figure 2}

Concentrations of chitinase 3-like protein 1 in CSF of MScl patients before (red) and after (blue) treatment with natalizumab as determined by ELISA. The concentration of this protein in CSF is significantly lower after treatment $(p=0.004)$. 
A

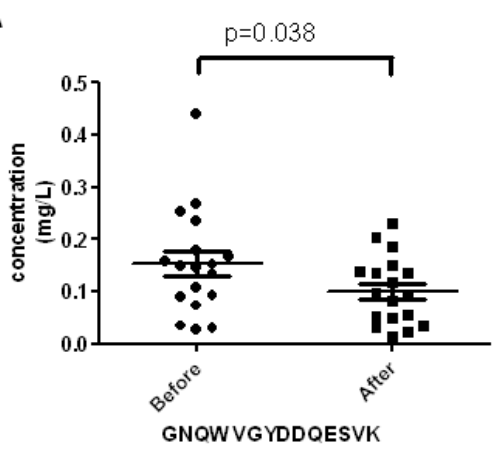

C
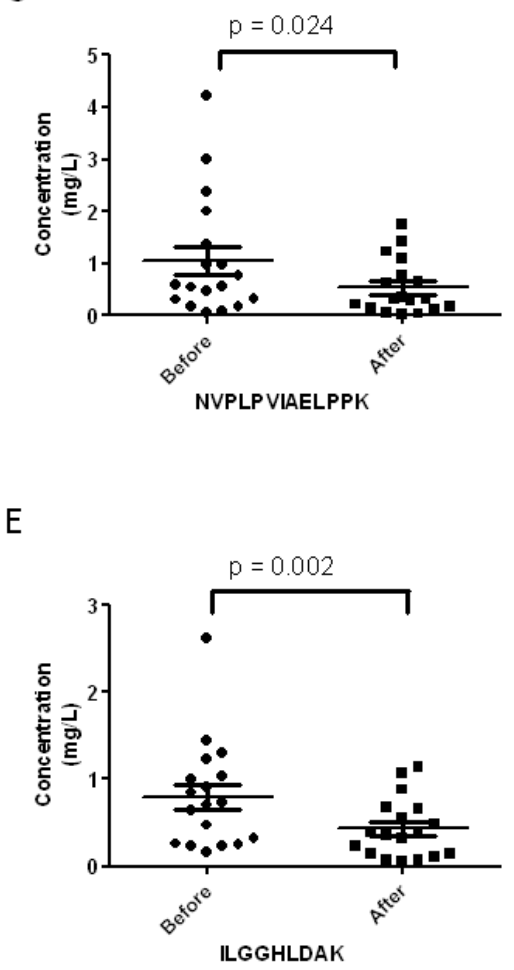

B

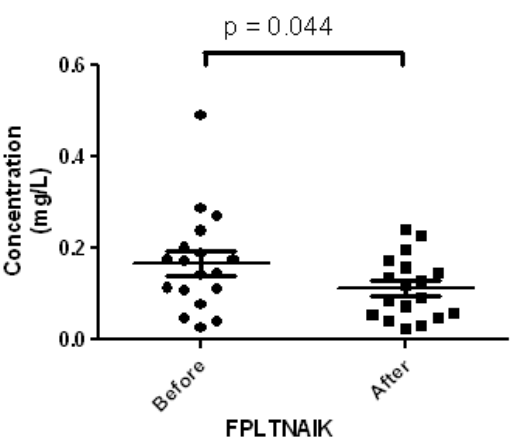

D

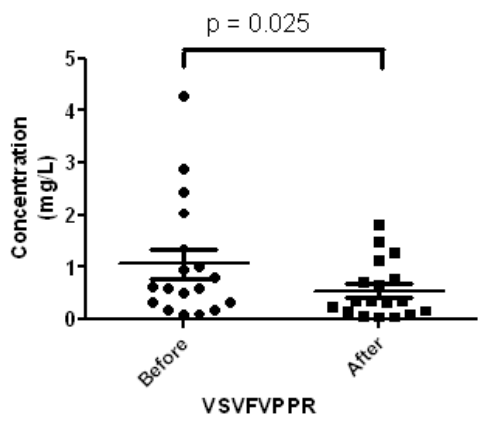




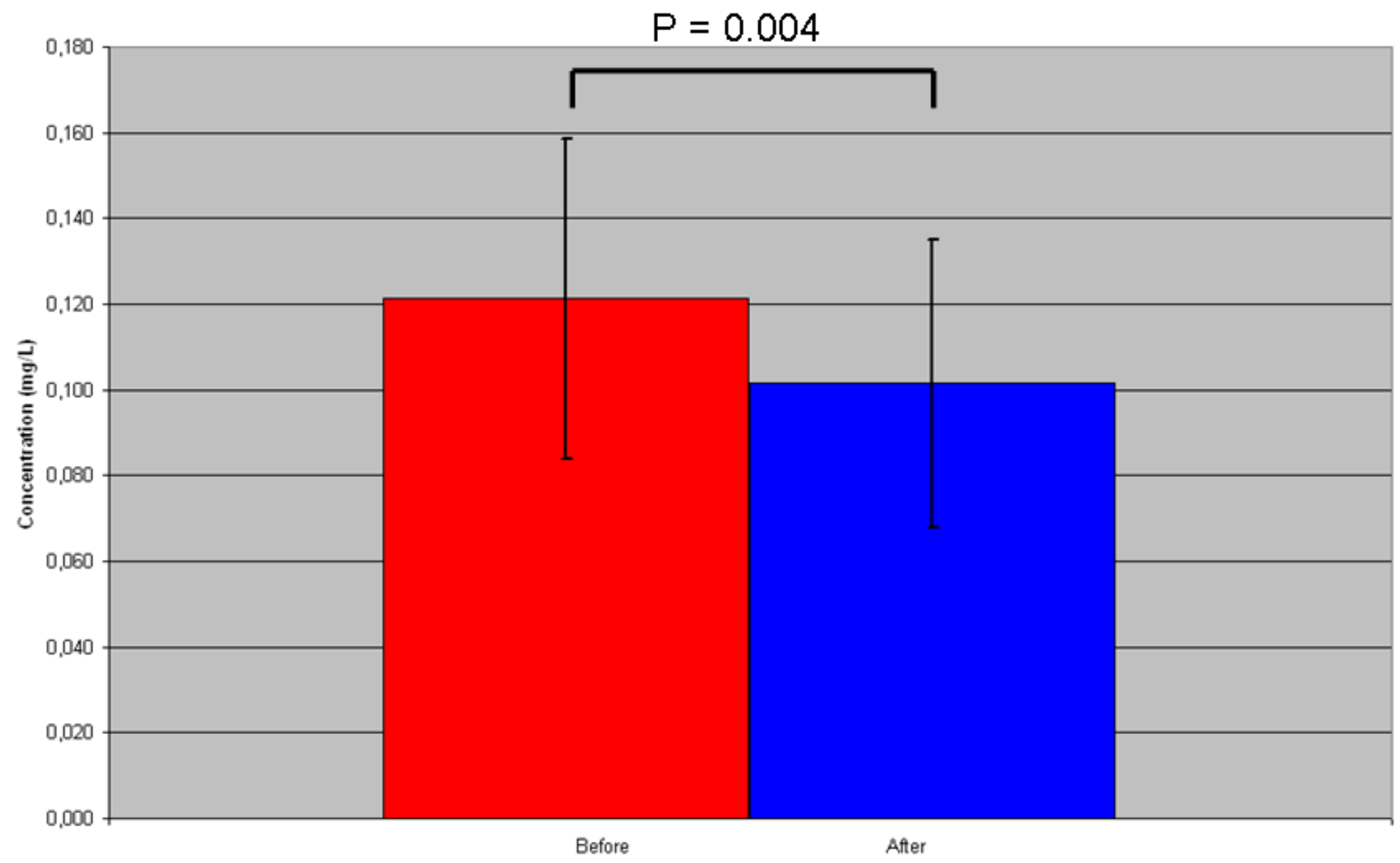


CSF discovery sample set

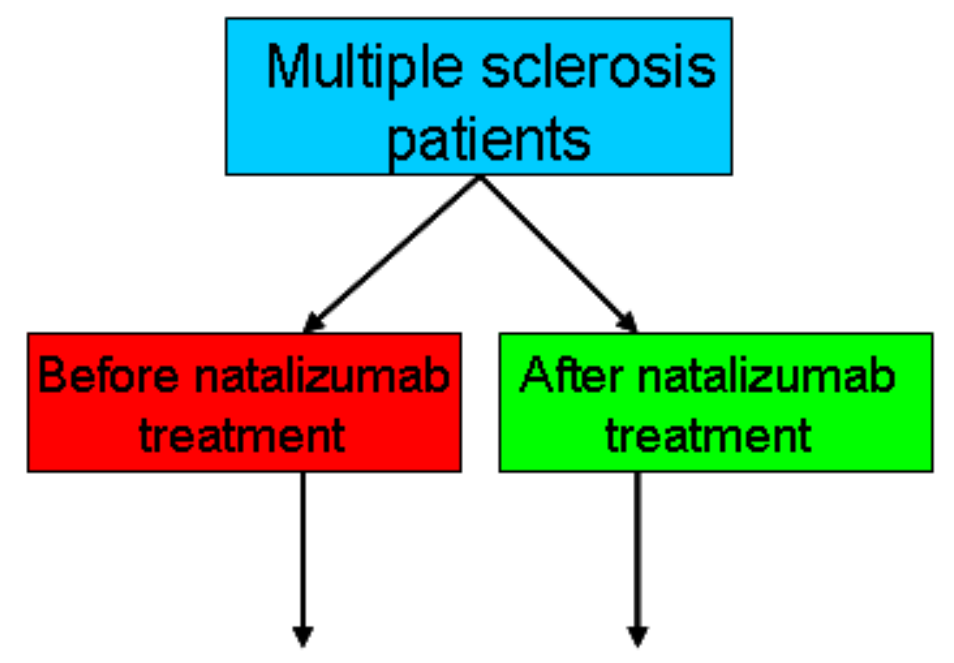

LC-MS and statistical analysis for differential abundant peptides and proteins

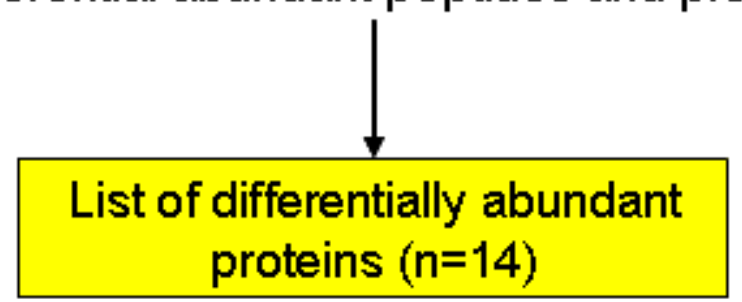

CSF validation sample set

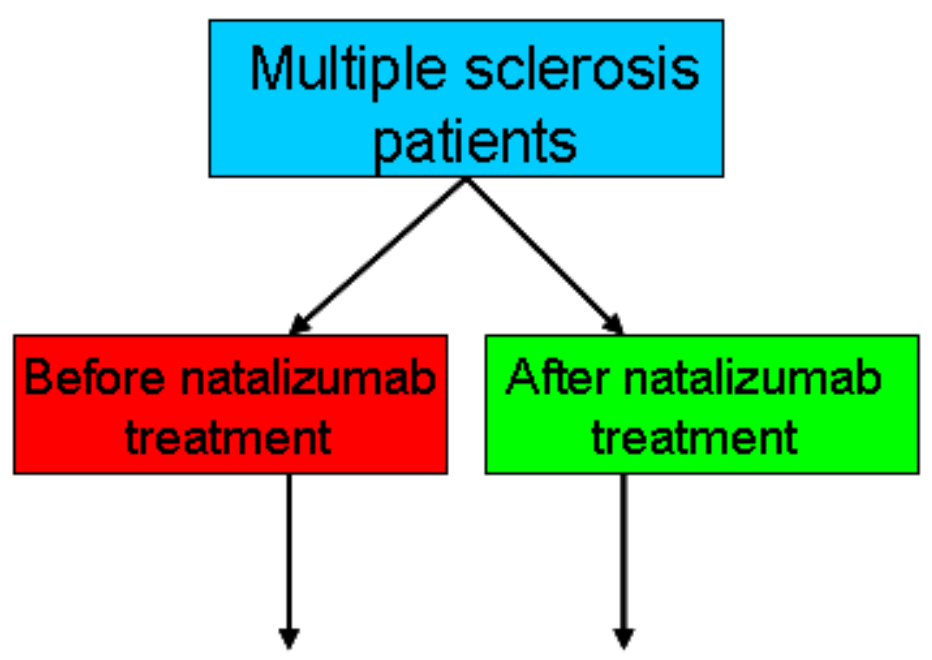

SRM and ELISA validation of three proteins identified in the discovery sample set

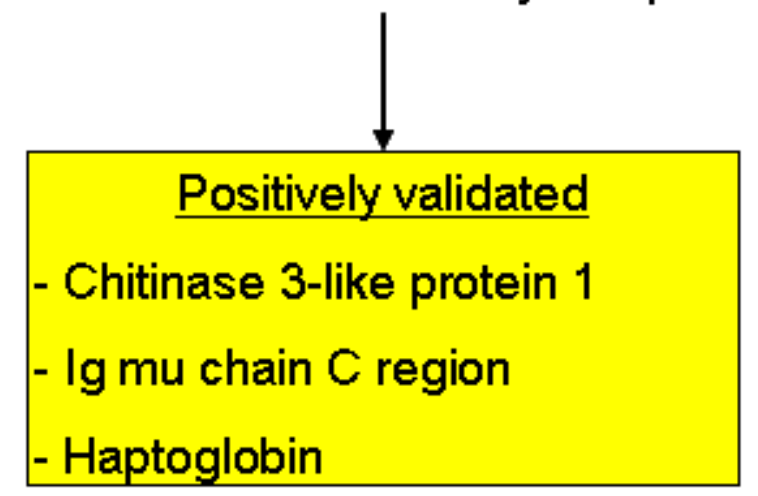

